\title{
Comparison of Intravitreal Bevacizumab versus Triamcinolone for the Treatment of Diffuse Diabetic Macular Edema
}

\author{
Thomas C. Kreutzer Rashid Al Saeidi Daniel Kook Armin Wolf \\ Michael W. Ulbig Aljoscha S. Neubauer Christos Haritoglou \\ Department of Ophthalmology, Ludwig-Maximilians University, Munich, Germany
}

\section{Key Words}

Bevacizumab · Triamcinolone - Diabetic macular edema

\begin{abstract}
Background: Our purpose was to compare the effect of triamcinolone and bevacizumab (Avastin) on the retinal thickness and functional outcome in patients with diabetic macular edema. Methods and Materials: A collective of 32 patients, who had been treated by a single $4.0-\mathrm{mg}$ intravitreal triamcinolone injection (group 1), was matched to 32 patients ('matched pairs'), who had received 3 injections of 1.25 $\mathrm{mg}$ of bevacizumab within 3 months in 4-week intervals (group 2). The outcome variables were changes in best corrected visual acuity (VA) and central retinal thickness 3 months after therapy. Results: Both groups did not differ regarding preoperative VA and central retinal thickness measured by optical coherence tomography. The baseline mean VA was $0.72 \pm 0.39 \log M A R$ in group 1 and $0.73 \pm 0.39 \mathrm{log}$ MAR in group $2(p=0.709)$. The mean central retinal thickness measured by optical coherence tomography was 548 $\pm 185 \mu \mathrm{m}$ in group 1 and $507 \pm 192 \mu \mathrm{m}$ in group 2 . While the patients in group 1 experienced a slight increase in VA of on average 0.7 lines following a single triamcinolone injection to a mean of $0.64 \pm 0.40 \log M A R(p=0.066)$ after 3 months, the patients in group 2 showed almost no effect on
\end{abstract}

VA with an average increase of 0.2 lines to a mean VA of 0.72 $\pm 0.30 \log M A R(p=0.948)$ following 3 intravitreal injections of bevacizumab. Comparing the effect on VA between both groups no statistically significant difference $(p=0.115)$ was noted. Concerning decrease in central retinal thickness both therapies were highly effective $(p<0.001$ each), again, without statistically significant difference between the groups $(p<0.128)$. Conclusion: Our data suggest that a single triamcinolone injection may be as effective as a 3 times repeated intravitreal administration of bevacizumab for the treatment of diabetic macular edema. Further prospective trials should be performed.

Copyright $\odot 2010$ S. Karger AG, Basel

\section{Introduction}

Diabetic retinopathy remains the major threat to sight in the working age population in the developed world. Furthermore, it is increasing as a major cause of blindness in other parts of the world, especially developing countries [1]. Diabetic macular edema is a manifestation

T.C.K. and R.A.S. contributed equally to the writing of the manuscript.

\section{KARGER}

Fax +41613061234 E-Mail karger@karger.ch www.karger.com
(C) 2010 S. Karger AG, Basel

$0030-3755 / 10 / 2244-0258 \$ 26.00 / 0$

Accessible online at:

www.karger.com/oph
Christos Haritoglou, MD

Department of Ophthalmology, Ludwig-Maximilian University

Mathildenstrasse 8, DE-80336 Munich (Germany)

Tel. +49 895160 3811, Fax +498951605160

E-Mail christos.haritoglou@med.uni-muenchen.de 
of diabetic retinopathy that accounts for the loss of central vision. Macular edema within 1 disc diameter of the fovea is present in $9 \%$ of the diabetic population. Although visual loss secondary to proliferative changes is more common in patients with type 1 diabetes, visual loss in patients with type 2 diabetes is more commonly due to macular edema. The development of diabetic retinopathy is a multifactorial process. Much of the retinal damage that characterizes the disease is now understood to result from retinal vascular leakage and nonperfusion mediated by numerous growth factors such as vascular endothelial growth factor (VEGF) $[2,3]$. Diabetic macular edema is caused by excessive vascular permeability, resulting in the leakage of fluid and plasma constituents, such as lipoproteins, into the retina, leading to its thickening. Therefore, drugs that counteract these mechanisms seem to be potential treatment options, such as steroids (e.g. triamcinolone) and anti-VEGF (e.g. bevacizumab) substances. Especially triamcinolone has been reported to effectively reduce the retinal thickness and increase the visual acuity (VA) in patients with diabetic macular edema [4]. Recently, bevacizumab has been introduced as a potential new drug in ophthalmology to successfully treat vascular diseases including age-related macular degeneration, retinal vein occlusion and diabetic macular edema [5-8]. The present study was performed to compare the effect of a single intravitreal injection of $4 \mathrm{mg}$ of triamcinolone versus 3 consecutive monthly intravitreal injections of $1.25 \mathrm{mg}$ of bevacizumab.

\section{Methods}

The present study was designed as a retrospective evaluation comparing 32 patients treated with a single intravitreal injection of triamcinolone ( $4.0 \mathrm{mg}$; group 1) versus 32 patients treated with 3 consecutive monthly intravitreal injections of bevacizumab (1.25 mg; group 2). The individuals for both groups were selected randomly from our database while being matched according to age, baseline VA and extent of central macular thickness measured by optical coherence tomography (OCT). The database includes a predefined data set of all patients being treated for macular diseases. The collected data comprise age, gender, best corrected VA, intraocular pressure (IOP; Goldmann tonometry), central retinal thickness (CRT) measurements by OCT III (Zeiss Stratus) and ophthalmic diagnosis. The 3-year data pool in May 2008 consisted of 2,433 patients. None of them had received a therapy for diffuse macular edema within a period of 6 months prior to either the injection of bevacizumab or triamcinolone. The data pool of the triamcinolone-treated patients with diffuse macular edema consisted of 167 participants, while that of the bevacizumab-treated patients comprised 59 people. Within these pools primarily 32 patients were randomly selected from the be- vacizumab-treated group $(32 / 59 ; 54 \%)$ and then matched with the patients form the triamcinolone group (32/167; 19\%).

A complete clinical examination prior to each injection was performed including measurement of best corrected VA with a numbers projecting chart (Moeller-Wedel M3000, Wedel, Germany), slit lamp examination, tonometry and measurement of retinal thickness using OCT (Stratus OCT; Carl Zeiss Meditec, Jena, Germany). Prior to the first injection a fluorescein angiography was also performed. The same examinations were repeated 3 months following the injection of triamcinolone and 4 weeks after the third administration of bevacizumab (3 months after the first injection).

All the patients provided written informed consent and were especially informed about the off-label character of the treatment and the potential risk of endophthalmitis and retinal detachment as well as the likelihood that additional treatments might be required. The Institutional Review Board had approved the present investigation.

\section{Injection Methods}

Before injection, topical anesthesia was induced by applying tetracaine (1\%) eye drops at least 3 times. The conjunctiva bulbi and the fornices were repeatedly irrigated with $1 \%$ povidoneiodine (Betadine ${ }^{\circledR}$, Alcon, Ft. Worth, Tex., USA). Povidone-iodine was also applied to the eyelid margins and the lashes, avoiding expression of the meibomian glands. After the application of a sterile drape, a lid speculum was inserted. The patients then either received a unilateral intravitreal injection of a $0.1-\mathrm{ml}$ volume containing $4 \mathrm{mg}$ of triamcinolone or a $0.05-\mathrm{ml}$ volume containing $1.25 \mathrm{mg}$ of bevacizmab using a sharp 27-gauge needle at a distance of $3.5 \mathrm{~mm}$ from the limbus in pseudophakic or $4.0 \mathrm{~mm}$ in phakic eyes, respectively. The needle was carefully removed using a sterile cotton applicator to prevent reflux. After injection, antibiotic eye drops (polymyxin and neomycin) were applied for 3 days 4 times per day. The drug was drawn under sterile conditions from a triamcinolone ampule or from a bevacizumab infusion bottle used for the systemic treatment of cancer patients by our pharmacy department and was not diluted further.

\section{Statistical Analysis}

Only 1 eye per subject was included in the study. All the data were collected on an MS-Excel 2000 spreadsheet (Microsoft Corporation, Redmond, Wash., USA) and analyzed using SPSS 13.0 for Windows (SPSS Inc., Chicago, Ill., USA). For the evaluation of unbounded groups with dichotomously distributed variables the $\chi^{2}$ and in case of multivariate variables the Mann-Whitney $U$ test (MWUT) were used. When bounded groups with multivariate variables were compared, the Wilcoxon test (WT) was applied. For all results the used statistical test is given in abbreviation. For all statistical tests, $\mathrm{p}<0.05$ was considered significant.

\section{Results}

\section{Subjects}

Both groups of patients matched according to the preoperative variables evaluated (table 1). The patients in both groups did not significantly differ considering 
Table 1. Characteristics of the individual groups

\begin{tabular}{lccc}
\hline & $\begin{array}{l}\text { Group 1 } \\
\text { (triamcinolone) }\end{array}$ & $\begin{array}{l}\text { Group 2 } \\
\text { (bevacizumab) }\end{array}$ & p value \\
\hline Gender (F/M) & $13 / 19$ & $17 / 15$ & $0.316^{1}$ \\
Age, years & $64.6 \pm 8.9$ & $64.8 \pm 11.6$ years & $0.545^{2}$ \\
HbA $_{1 \mathrm{C}, \% m l}$ & $7.1 \pm 0.80$ & $7.0 \pm 0.75$ & $0.778^{2}$ \\
Blood pressure (systolic/diastolic) & $138.0 \pm 10.9 / 85.8 \pm 8.9$ & $139.9 \pm 10.6 / 84.4 \pm 9.5$ & $0.454 / 0.549^{2}$ \\
Duration of macular edema, weeks & $78.7 \pm 29.6$ & $81.9 \pm 31.2$ & $0.586^{2}$ \\
Baseline VA & $20 / 80(20 / 1,000-20 / 33)$ & $20 / 80(20 / 1,000-20 / 33)$ & $0.709^{2}$ \\
Three-month VA & $20 / 66(20 / 1,000-20 / 20)$ & $20 / 80(20 / 400-20 / 25)$ & $0.202^{2}$ \\
Baseline CRT, $\mu \mathrm{m}$ & $548 \pm 185$ & $507 \pm 192$ & $0.310^{2}$ \\
Three-month CRT, $\mu \mathrm{m}$ & $365 \pm 154$ & $402 \pm 147$ & $0.204^{2}$ \\
\hline
\end{tabular}

Figures are means $\pm \mathrm{SD}$ and values in parentheses represent ranges. ${ }^{1} \chi^{2}$ test. ${ }^{2}$ Mann-Whitney $\mathrm{U}$ test.

age, gender, baseline VA and CRT. In group 1 (triamcinolone), 29 (91\%) of 32 eyes were phakic and 3 eyes pseudophakic, while in group 2 (bevacizumab) 26 (81\%) of 32 eyes were phakic and 6 eyes pseudophakic $(\mathrm{p}=$ $0.474 ; \chi^{2}$ test). In group 1 , clinically relevant cataract formation in the 29 phakic eyes at baseline was seen in 13 cases (45\%), compared to 11 cases of 26 phakic eyes (42\%) in group 2 ( $\mathrm{p}=0.534 ; \chi^{2}$ test). After 3 months, a progression of cataract formation was seen in 7 (24\%) of 29 phakic eyes in group 1 and $3(11.5 \%)$ of 26 phakic eyes in group $2\left(\mathrm{p}=0.196 ; \chi^{2}\right.$ test $)$. All the patients had chronic diffuse macular edema. No significant differences in blood pressure values as well as long-term blood sugar were observed.

\section{Retinal Thickness}

The mean CRT at baseline measured by OCT was 548 $\pm 185 \mu \mathrm{m}($ range $=264-800)$ in group 1 and $507 \pm 192$ $\mu \mathrm{m}$ (range $=213-1,031)$ in group 2 . At the 3 -month control visit the patients in group 1 showed a significant decrease in mean CRT to $365 \pm 154 \mu \mathrm{m}$ (range $=192$ $800, \mathrm{p}<0.001$; WT; fig. 1 ), as did those of group 2 with a significant reduction in CRT to $402 \pm 147 \mu \mathrm{m}$ (range $=192-830, \mathrm{p}<0.001$; WT; fig. 2). Statistical analysis showed no significant difference between both groups concerning CRT at baseline and 3 months and decrease in CRT over 3 months $(\mathrm{p}=0.310, \mathrm{p}=0.204$, $\mathrm{p}=0.128$, respectively; MWUT; fig. 3 ). The documented duration of macular edema in group 1 was $78.7 \pm 29.6$ weeks as compared to $81.9 \pm 31.2$ weeks in group $2(\mathrm{p}=$ $0.586)$.

\section{Visual Acuity}

At baseline, a VA of $0.72 \pm 0.39 \log$ MAR in group 1 and $0.73 \pm 0.39 \log$ MAR in group $2(\mathrm{p}=0.709$; MWUT $)$ was measured. While the patients in group 1 experienced a slight increase in VA following a single intravitreal triamcinolone injection of on average 0.7 lines to a mean of $0.64 \pm 0.40 \operatorname{logMAR}(\mathrm{p}=0.066$; WT) after 3 months, those in group 2 following 3 injections of bevacizumab showed almost no effect on VA with an average increase of 0.2 lines to a mean VA of $0.72 \pm 0.30 \log$ MAR ( $p=$ 0.948; WT; fig. 4). Neither baseline VA, nor VA after 3 months, nor the change in VA from baseline to the 3 -month control visit was statistically significantly different comparing both groups $(\mathrm{p}=0.709, \mathrm{p}=0.212, \mathrm{p}=$ 0.115 , respectively; MWUT).

\section{Adverse Events}

We did not observe any adverse events that could be related to the injection itself or the medication used. The measurement of IOP showed a mean of $13.5 \mathrm{~mm} \mathrm{Hg}$ preoperatively in group 1 and $13.3 \mathrm{~mm} \mathrm{Hg}$ in group 2 compared to $14.1 \mathrm{~mm} \mathrm{Hg}$ after 3 months in group 1 and 13.7 $\mathrm{mm} \mathrm{Hg}$ in group 2. Of note, even in patients treated with triamcinolone, no relevant elevation of IOP requiring medical treatment was noted.

\section{Discussion}

Diffuse chronic macular edema in diabetic retinopathy often leads to poor prognosis concerning VA [9]. In the Early Treatment Diabetic Retinopathy Study, grid la- 


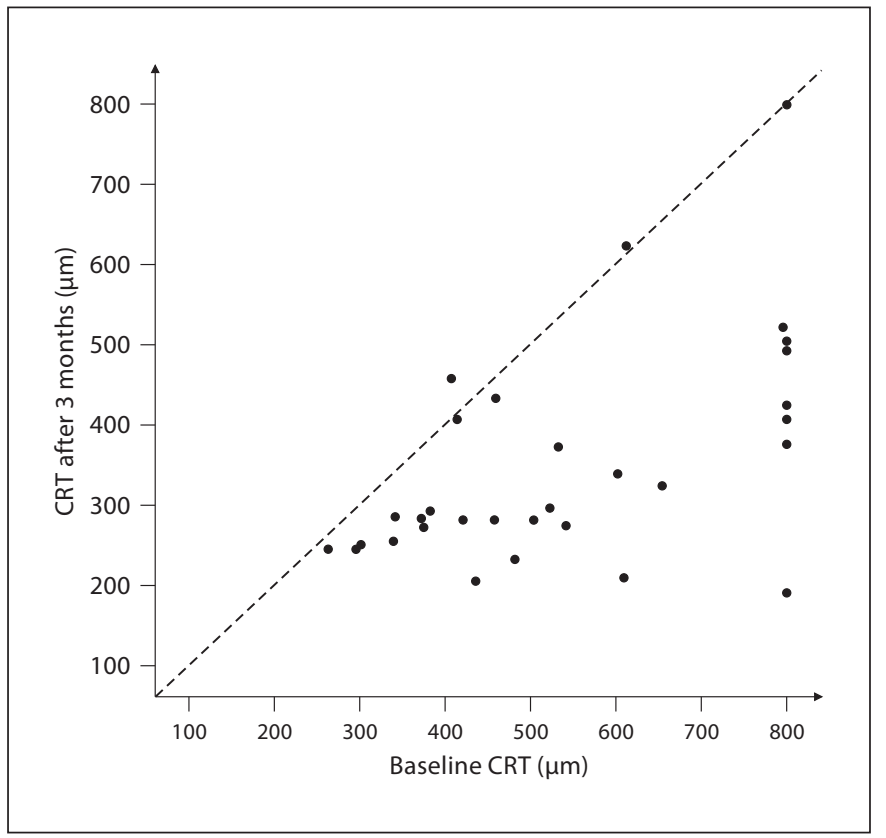

Fig. 1. Scatterplot of CRT results measured by OCT in triamcinolone-treated eyes.

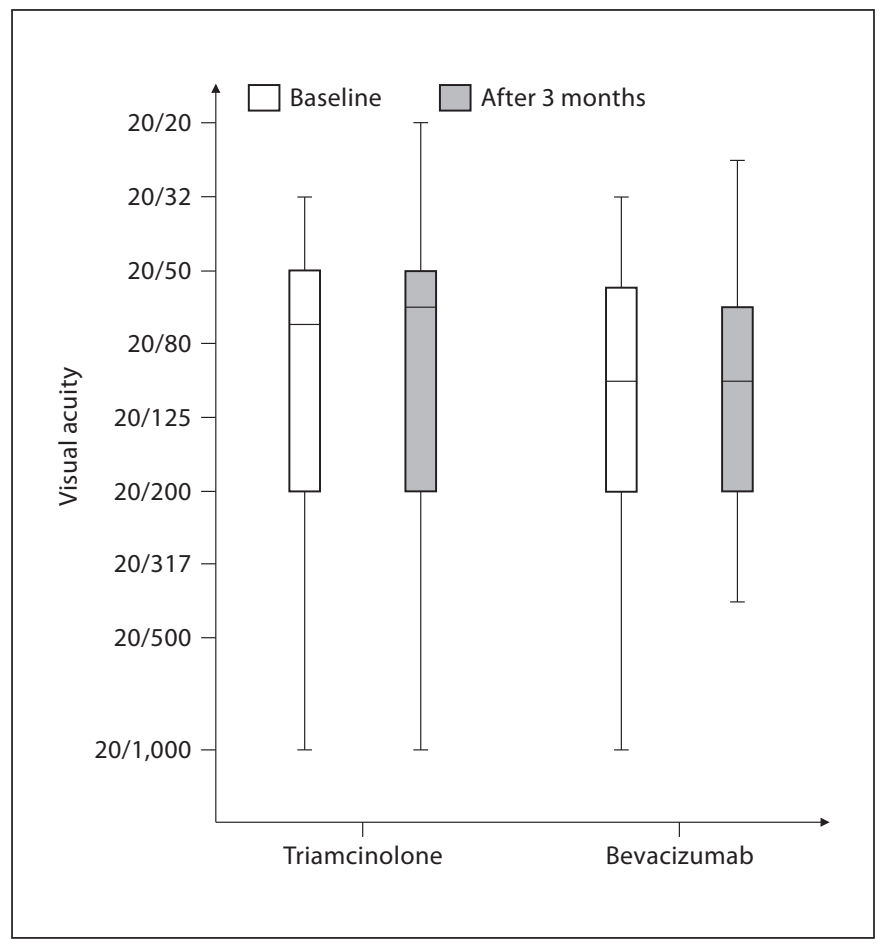

Fig. 3. Boxplot of CRT results measured by OCT comparing triamcinolone- and bevacizumab-treated eyes. Boxes represent values within the 25 and $75 \%$ percentile, while the line inside the box indicates the median.

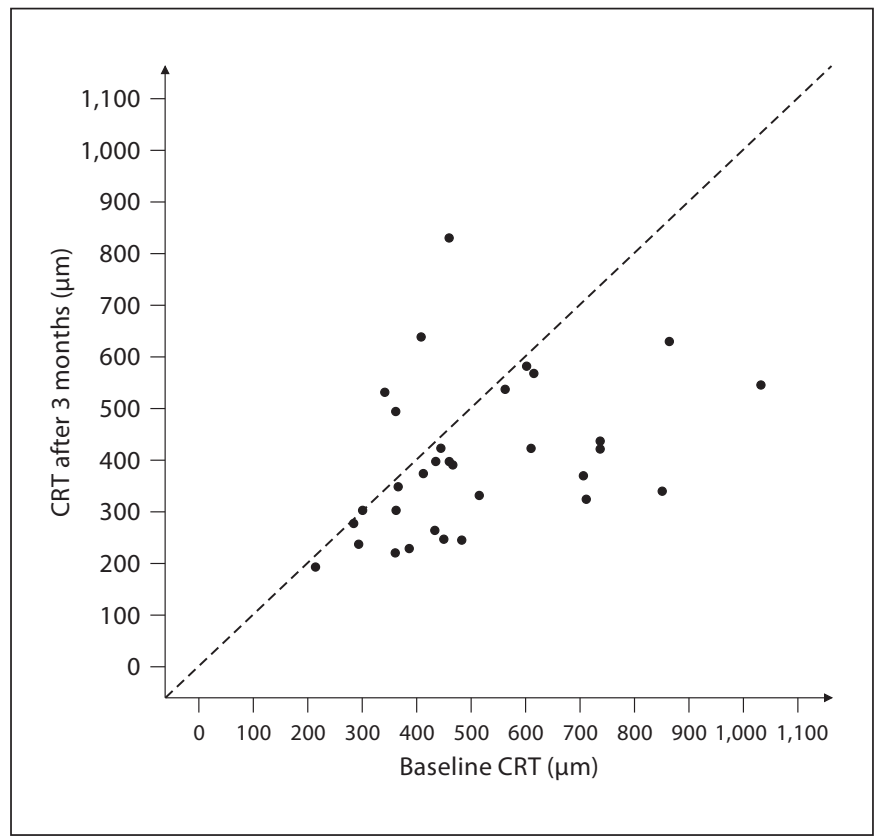

Fig. 2. Scatterplot of CRT results measured by OCT in bevacizumab-treated eyes.

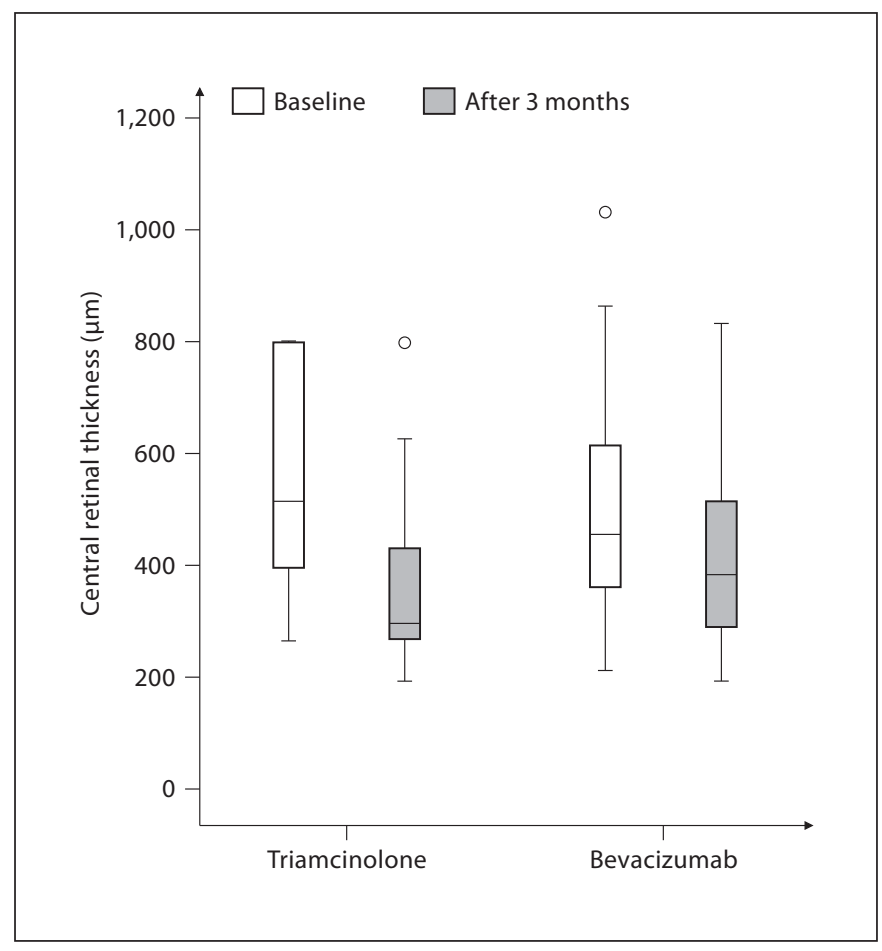

Fig. 4. Boxplot of VA scores comparing triamcinolone- and bevacizumab-treated eyes. Boxes represent values within the 25 and $75 \%$ percentile, while the line inside the box indicates the median. 
ser photocoagulation was recommended for patients with diffuse diabetic macular edema [10]. As the effectiveness concerning visual recovery varies, new therapeutic strategies have been proposed in order to improve the visual outcome.

Intravitreally injected triamcinolone, a corticosteroid, has been successfully used for the therapy of chronic diffuse diabetic macular edema $[4,11-15]$. Triamcinolone reduces VEGF expression, vascular leakage and inflammatory responses, all factors known to play a role in the pathogenesis of diabetic macular edema $[16,17]$. One major drawback of its use is the high rate of complications, such as cataract formation and marked elevation of IOP [18]. Supported by a number of experimental studies [1924], VEGF inhibitors have been introduced for the treatment of various retinal vascular diseases. Bevacizumab is a humanized monoclonal antibody that binds to all subforms of VEGF [25]. Recent studies have described the effectiveness of bevacizumab and other anti-VEGF drugs to reduce chronic diabetic macular edema and increase VA in these eyes $[7,26,27]$.

Our study describes the effect of a single injection of $4 \mathrm{mg}$ of triamcinolone versus 3 injections of $1.25 \mathrm{mg}$ of bevacizumab in patients with diabetic macular edema. We observed a significant reduction in retinal thickness using both treatments, with a more pronounced effect seen following the treatment with triamcinolone. No statistically significant difference in the duration of macular edema was observed in the 2 groups. Despite this promising result, no statistically significant improvement in VA was seen in both groups. This result might be due to the composition of the selected individuals. As both drugs are considered 'off-label' for intraocular use, most eyes treated were cases resistant to established therapeutic approaches such as laser photocoagulation or pars plana vitrectomy. The patients included in this investigation somehow represent a 'negative' selection, which may influence the treatment effect both concerning changes in VA and CRT.

Though eyes treated with triamcinolone showed a slight increase in VA, this result did just not reach statistical significance $(\mathrm{p}=0.066)$, which may be related to the relatively small sample size used in this study or the case selection as mentioned. However, previous studies have shown the positive effect of triamcinolone on VA in patients with diffuse diabetic macular edema [4].

Besides the comparison of the effectiveness of monotherapies for diabetic macular edema as described herein, other investigators recently analyzed the effect of a combination of a single intravitreal bevacizumab injection alone or in combination with intravitreal triamcinolone versus macular laser photocoagulation as primary treatment of diabetic macular edema [28]. They observed that a treatment with intravitreal bevacizumab provided a better visual outcome than laser photocoagulation, although it was not associated with a significant decrease in central macular thickness. No further beneficial effect of intravitreal triamcinolone could be demonstrated. A phase II randomized clinical trial evaluating the effect of intravitreal bevacizumab for diabetic macular edema in different dosages and combination with photocoagulation compared to photocoagulation alone also showed a beneficial effect of bevacizumab on retinal thickness and VA [29]. In this study, combining focal photocoagulation with bevacizumab did not result in any apparent shortterm benefit or adverse outcomes.

Due to the relatively small number of participants included in the present study, treatment-related differences could not be analyzed with regard to stages of the disease, type of diabetes and other factors. However, the patients were very well matched concerning the relevant ophthalmologic factors we wanted to examine. Our results seem especially interesting with respect to the treatment regime applied, with a single steroid injection showing a significant anatomic effect in contrast to 3 anti-VEGF injections. Fewer injections may not only reduce the risk of adverse events such as endophthalmitis but can also be managed more easily by the involved personnel in offices and hospitals and of course help improve the patients' quality of life. However, the present study aimed at an evaluation of the efficacy of the treatment applied and did not focus on potential safety concerns implicated in the use especially of triamcinolone, including cataract formation and elevation of IOP. These points were addressed in former trials $[18,30]$.

A drawback of our study is the short period of followup. Further investigation is needed to evaluate the relevance of additional intravitreal injections of either triamcinolone or bevacizumab. It would be interesting to know if a combined treatment of an initial injection of triamcinolone followed by intravitreal injections of bevacizumab is efficient enough to maintain the therapeutic effect observed for triamcinolone, especially as other authors recently observed no further beneficial effect of intravitreal triamcinolone being injected following bevacizumab [28]. In addition, triamcinolone-related complications may be eliminated by switching to injecting prednisolone sodium succinate intravitreally [31]. A very recent study compared the effect of intravitreal triamcinolone injections (1 vs. $4 \mathrm{mg}$ ) and focal laser coagula- 
tion: over a 2-year period, focal/grid photocoagulation appeared more effective and revealed fewer side effects than 1- or 4-mg doses of preservative-free intravitreal triamcinolone for most patients with diabetic macular edema [32]. However, this report did not differentiate between different types of macular edema (focal or diffuse), which may have implications for the treatment applied and the success of the respective treatment observed. In contrast, we included only patients with diffuse diabetic macular edema in our study.
In summary, we could demonstrate a significant impact on retinal thickness following a single injection of triamcinolone or 3 injections of bevacizumab in patients with diabetic macular edema. A trend towards better VA results was seen for triamcinolone- but not for bevacizumab-treated patients. We conclude from our analysis that the effect of both treatment strategies should be evaluated further in a prospective study setting, including patients with less severe stages of the disease, as they may benefit more especially in terms of visual recovery as well as combinations of the treatment modalities.

\section{References}

1 Harris MI: Diabetes in America: epidemiology and scope of the problem. Diabetes Care 1998;21(suppl 3):C11-C14.

2 Adamis AP, Miller JW, Bernal MT, D’Amico DJ, Folkman J, Yeo TK, Yeo KT: Increased vascular endothelial growth factor levels in the vitreous of eyes with proliferative diabetic retinopathy. Am J Ophthalmol 1994;118: $445-450$.

3 Joussen AM, Poulaki V, Le ML, Koizumi K, Esser C, Janicki H, Schraermeyer U, Kociok N, Fauser S, Kirchhof B, Kern TS, Adamis AP: A central role for inflammation in the pathogenesis of diabetic retinopathy. FASEB J 2004;18:1450-1452.

4 Audren F, Erginay A, Haouchine B, Benosman R, Conrath J, Bergmann JF, Gaudric A, Massin P: Intravitreal triamcinolone acetonide for diffuse diabetic macular oedema: 6-month results of a prospective controlled trial. Acta Ophthalmol Scand 2006;84:624630.

5 Avery RL, Pieramici DJ, Rabena MD, Castellarin AA, Nasir MA, Giust MJ: Intravitreal bevacizumab (avastin) for neovascular agerelated macular degeneration. Ophthalmology 2006;113:363-372, e365.

6 Emerson MV, Lauer AK, Flaxel CJ, Wilson DJ, Francis PJ, Stout JT, Emerson GG, Schlesinger TK, Nolte SK, Klein ML: Intravitreal bevacizumab (avastin) treatment of neovascular age-related macular degeneration. Retina 2007;27:439-444.

7 Haritoglou C, Kook D, Neubauer A, Wolf A, Priglinger S, Strauss R, Gandorfer A, Ulbig M, Kampik A: Intravitreal bevacizumab (avastin) therapy for persistent diffuse diabetic macular edema. Retina 2006;26:9991005.

8 Priglinger SG, Wolf AH, Kreutzer TC, Kook D, Hofer A, Strauss RW, Alge CS, Kunze C, Haritoglou C, Kampik A: Intravitreal bevacizumab injections for treatment of central retinal vein occlusion: six-month results of a prospective trial. Retina 2007;27:10041012.
9 Patz A, Schatz H, Berkow JW, Gittelsohn AM, Ticho U: Macular edema - an overlooked complication of diabetic retinopathy Trans Am Acad Ophthalmol Otolaryngol 1973;77:OP34-OP42.

10 Early Treatment Diabetic Retinopathy Study Research Group: Focal photocoagulation treatment of diabetic macular edema: relationship of treatment effect to fluorescein angiographic and other retinal characteristics at baseline: ETDRS report No 19. Arch Ophthalmol 1995;113:1144-1155.

11 Audren F, Lecleire-Collet A, Erginay A Haouchine B, Benosman R, Bergmann JF, Gaudric A, Massin P: Intravitreal triamcinolone acetonide for diffuse diabetic macular edema: phase 2 trial comparing $4 \mathrm{mg}$ vs $2 \mathrm{mg}$. Am J Ophthalmol 2006;142:794-799.

12 Brasil OF, Smith SD, Galor A, Lowder CY, Sears JE, Kaiser PK: Predictive factors for short-term visual outcome after intravitreal triamcinolone acetonide injection for diabetic macular oedema: an optical coherence tomography study. Br J Ophthalmol 2007;91: 761-765.

13 Gibran SK, Cullinane A, Jungkim S, Cleary PE: Intravitreal triamcinolone for diffuse diabetic macular oedema. Eye 2006;20:720724.

14 Jonas JB, Akkoyun I, Kreissig I, Degenring RF: Diffuse diabetic macular oedema treated by intravitreal triamcinolone acetonide: a comparative, non-randomised study. $\mathrm{Br} \mathrm{J}$ Ophthalmol 2005;89:321-326.

15 Jonas JB, Kamppeter BA, Harder B, Vossmerbaeumer U, Sauder G, Spandau UH: Intravitreal triamcinolone acetonide for diabetic macular edema: a prospective, randomized study. J Ocul Pharmacol Ther 2006; 22:200-207.

16 Matsuda S, Gomi F, Oshima Y, Tohyama M, Tano Y: Vascular endothelial growth factor reduced and connective tissue growth factor induced by triamcinolone in ARPE19 cells under oxidative stress. Invest Ophthalmo Vis Sci 2005;46:1062-1068.
17 Zhang X, Bao S, Lai D, Rapkins RW, Gillies MC: Intravitreal triamcinolone acetonide inhibits breakdown of the blood-retinal barrier through differential regulation of VEGF-A and its receptors in early diabetic rat retinas. Diabetes 2008;57:1026-1033.

18 Thompson JT: Cataract formation and other complications of intravitreal triamcinolone for macular edema. Am J Ophthalmol 2006; 141:629-637.

19 Ferrara N, Hillan KJ, Novotny W: Bevacizumab (avastin), a humanized anti-VEGF monoclonal antibody for cancer therapy. Biochem Biophys Res Commun 2005;333: 328-335.

20 Ishizaki E, Takai S, Ueki M, Maeno T, Maruichi M, Sugiyama T, Oku H, Ikeda T, Miyazaki M: Correlation between angiotensin-converting enzyme, vascular endothelial growth factor, and matrix metalloproteinase-9 in the vitreous of eyes with diabetic retinopathy. Am J Ophthalmol 2006;141: 129-134.

21 Kakehashi A, Inoda S, Mameuda C, Kuroki M, Jono T, Nagai R, Horiuchi S, Kawakami M, Kanazawa Y: Relationship among VEGF, VEGF receptor, AGEs, and macrophages in proliferative diabetic retinopathy. Diabetes Res Clin Pract 2007;79:438-445.

22 Mason JO 3rd, Nixon PA, White MF: Intravitreal injection of bevacizumab (avastin) as adjunctive treatment of proliferative diabetic retinopathy. Am J Ophthalmol 2006;142: 685-688.

23 Mysliwiec M, Balcerska A, Zorena K, Mysliwska J, Lipowski P, Raczynska K: The role of vascular endothelial growth factor, tumor necrosis factor $\alpha$ and interleukin- 6 in pathogenesis of diabetic retinopathy. Diabetes Res Clin Pract 2008;79:141-146.

24 Sawada O, Kawamura H, Kakinoki M, Sawada T, Ohji M: Vascular endothelial growth factor in aqueous humor before and after intravitreal injection of bevacizumab in eyes with diabetic retinopathy. Arch Ophthalmol 2007;125:1363-1366. 
25 Starita C, Patel M, Katz B, Adamis AP: Vascular endothelial growth factor and the potential therapeutic use of pegaptanib (macugen) in diabetic retinopathy. Dev Ophthalmol 2007;39:122-148.

26 Arevalo JF, Fromow-Guerra J, Quiroz-Mercado H, Sanchez JG, Wu L, Maia M, Berrocal $\mathrm{MH}$, Solis-Vivanco A, Farah ME: Primary intravitreal bevacizumab (avastin) for diabetic macular edema: results from the PanAmerican Collaborative Retina Study Group at 6-month follow-up. Ophthalmology 2007; 114:743-750.
27 Cunningham ET Jr, Adamis AP, Altaweel M, Aiello LP, Bressler NM, D’Amico DJ, Goldbaum M, Guyer DR, Katz B, Patel M, Schwartz SD: A phase II randomized doublemasked trial of pegaptanib, an anti-vascular endothelial growth factor aptamer, for diabetic macular edema. Ophthalmology 2005; 112:1747-1757.

28 Soheilian M, Ramezani A, Bijanzadeh B, Yaseri M, Ahmadieh H, Dehghan MH, Azarmina M, Moradian S, Tabatabaei H, Peyman GA: Intravitreal bevacizumab (avastin) injection alone or combined with triamcinolone versus macular photocoagulation as primary treatment of diabetic macular edema. Retina 2007;27:1187-1195.

29 Scott IU, Edwards AR, Beck RW, Bressler NM, Chan CK, Elman MJ, Friedman SM, Greven CM, Maturi RK, Pieramici DJ, Shami M, Singerman LJ, Stockdale CR: A phase II randomized clinical trial of intravitreal bevacizumab for diabetic macular edema. Ophthalmology 2007;114:1860-1867.
30 Jonas JB, Degenring RF, Kreissig I, Akkoyun I, Kamppeter BA: Intraocular pressure elevation after intravitreal triamcinolone acetonide injection. Ophthalmology 2005;112:593598.

31 La Heij EC, Lundqvist IJ, Berendschot TT, Hardy E, Liem AT, Hendrikse F: Intravitreal prednisolone sodium succinate reduces diabetic macular edema without intraocular pressure rise. Am J Ophthalmol 2007;143: 176-178.

32 A randomized trial comparing intravitreal triamcinolone acetonide and focal/grid photocoagulation for diabetic macular edema. Ophthalmology 2008;115:1447-1449, 1449. e1-10. 